\title{
Acute Myeloid Leukemia with Myelodysplasia-Related Changes
}

National Cancer Institute

\section{Source}

National Cancer Institute. Acute Myeloid Leukemia with Myelodysplasia-Related Changes. NCl Thesaurus. Code C7600.

An acute myeloid leukemia with at least $20 \%$ blasts in the bone marrow or blood, and either a previous history of myelodysplastic syndrome, multilineage dysplasia or myelodysplastic syndrome-related cytog enetic abnormalities. There is no history of prior cytotoxic therapy for an unrelated disorder, and there is absence of the cytogenetic abnormalities that are present in acute myeloid leukemia with recurrent genetic abnormalities. 